\title{
DESIGN OF HEATING EQUiPMENT FOR MOULDING ORganic POLYMER-BASEd COMPOSITES
}

\author{
Stepan Jenicek, Vratislav Kotesovec, Tomas Kalina \& Katerina Opatova
}
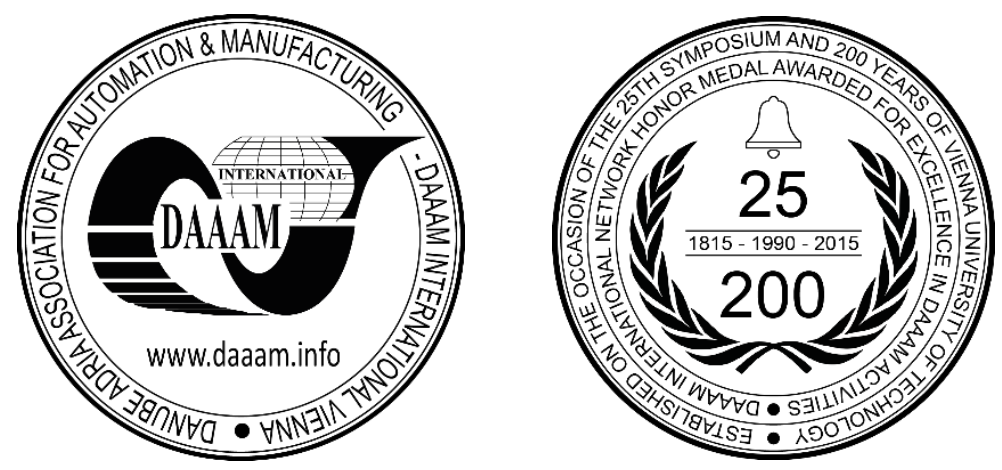

This Publication has to be referred as: Jenicek, S[tepan]; Kotesovec, V[ratislav]; Kalina, T[omas] \& Opatova, K[aterina] (2018). Design of Heating Equipment for Moulding Organic Polymer-Based Composites, Proceedings of the 29th DAAAM International Symposium, pp.0273-0278, B. Katalinic (Ed.), Published by DAAAM International, ISBN 978-3-902734-20-4, ISSN 1726-9679, Vienna, Austria

DOI: $10.2507 / 29$ th.daaam.proceedings.039

\begin{abstract}
Polymer composites are materials whose importance and scope of applications are growing continuously. Where permitted by the service conditions, conventional materials tend to be substituted with composites. Another common trend seen today is to minimize or eliminate adverse impacts of manufacturing on the environment. It has led to a wider adoption of recyclable filler materials for composites. Unfortunately, their composition is not always consistent, which often has an adverse impact on the moulding process and the resultant mechanical properties. In order to understand this impact, heating equipment for moulding organic polymer-based composite materials was proposed and designed. In this design, the construction, electronic equipment and process control aspects had to be considered. Since its control unit should operate in real time, the NI myRIO-1900 device was chosen. The software control was programmed in the LabVIEW environment. The reason for choosing this configuration was that its control loop was able to be adjusted and fine-tuned. NI myRIO-1900 supports access to a data network and communication with additional laboratory devices.
\end{abstract}

Keywords: heating; composite material; matrix; LabVIEW

\section{Introduction}

One of the trends of the modern era is the increasing use of composite materials which enable breakthrough solutions to be utilized in product development. This can be seen in all mechanical engineering disciplines. The sectors in which composites are of greatest importance include aircraft engineering, automotive industry (car interior and exterior, power unit) and the manufacture of watercraft of all kinds. In aircraft engineering, this concerns both secondary and primary structures. The materials that made up the Boeing 777 airplane comprised $12 \%$ composites and $50 \%$ aluminium. However, already the composition of Boeing 787 is very different: $50 \%$ composites, 20\% aluminium, $15 \%$ titanium, $10 \%$ steel and 5\% other materials [1]. Composites are becoming more and more common in the construction of chemical and power generation machines and equipment (pumps, desulphurization units and others) and manufacturing machines (e.g. spindles of machine tools) [3]. The importance and scope of applications of polymer composites are growing continuously. Where permitted by the service conditions, conventional materials are substituted with composites. 
Polymers and composites not only enable designers to meet the fundamental requirement of reduced weight, which is imposed on almost all applications, but also offer greater design freedom and room for innovation. Another endeavour of today is to minimize or eliminate adverse impacts of manufacturing on the environment. It has led to a more frequent use of recyclable filler materials. Unfortunately, their composition is not always consistent which often has adverse impact on the manufacturing process and the resultant mechanical properties. In order to understand this impact, heating equipment for moulding organic polymer-based composite materials had to be proposed and designed.

The problem is, that there is not commercially available heating equipment for composite materials of this type, that would meet desired experimental requirements. Therefore the aim of this article is to describe the problematics of heating design for this type of material. To determine the effect of recyclable fillers the specimen will be heated in the proposed device first and then it will be transferred to the facility where the elastic-plastic behaviour of the material during forming is examined. Measurements of the elastic-plastic properties will be performed on a thermo-mechanical simulator [9].

\section{Technology of manufacturing and moulding organic polymer-based composites}

Although a modern process, it is being studied by only a handful of research organisations. Nevertheless, it is evolving rapidly and offers an as yet unexplored potential. The method of manufacture and moulding of a composite part strongly affects the structure and properties of the product. These include the properties of the matrix, the matrixfiller interface, the filler geometry and other aspects. Organic polymer-based composites are made by mechanically mixing their constituents. This is how they differ from metal alloys, which are heterogeneous as well but the new phases in them come to existence through phase transformations, such as those that accompany solidification. There is a vast range of methods of manufacture of composite parts. The most common classification is based on the mould type:

- Open (integral) mould

- Closed (two-part) mould

The choice of the mould depends on the type of filler (short fibres, long fibres, 2D fabric or other) and on the matrix. The polymer matrices can be either thermoplastics or thermosets [2].

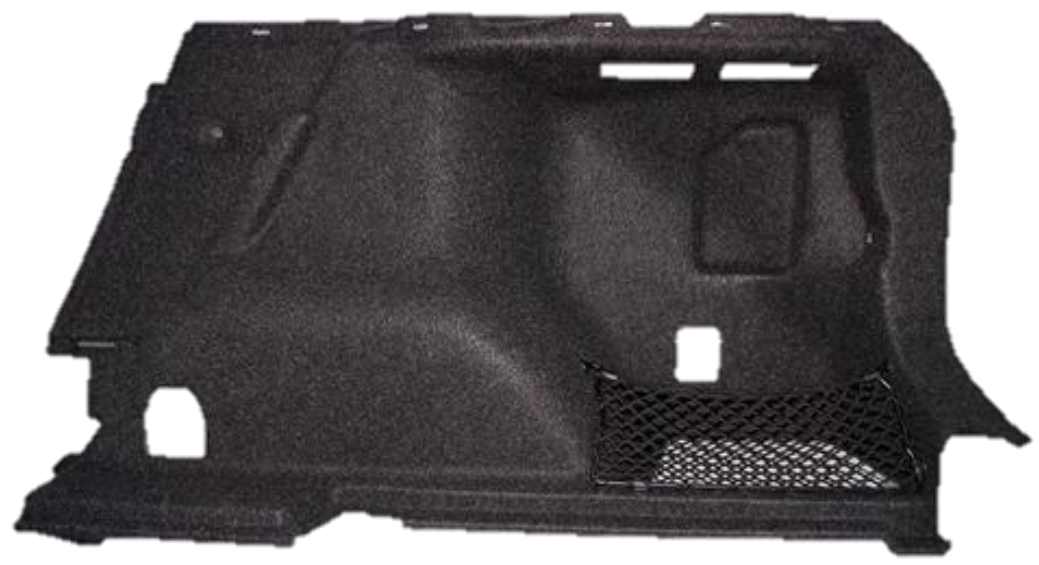

Fig. 1. Side lining of a car boot

In today's industrial practice, composites are manufactured in a single step together with the final product. Hence, the properties of the composite material as such cannot be considered separate from the utility properties of the entire product [4]. Consequently, the selection of the manufacturing sequence is inseparable from the design of a new composite material. However, if a composite material can be shaped in a separate subsequent step, new opportunities arise for modifying its properties and, consequently, the properties of the final product. This newly-designed heating equipment is intended for moulding in a two-part mould which can be heated and cooled. The blank is a composite, consisting of a hard sheet of approx. $1 \mathrm{~mm}$ thickness and a non-woven fabric which covers one side of the sheet. Both materials are polymers.

The composite is designed for the manufacture of mouldings for various sectors, including the automotive industry (Fig. 1). It can facilitate and speed up the production, when compared to the processing of separate constituents. Understandably, it is not a classical composite for load-bearing parts. Here, the fabric fulfils aesthetic and noise insulation roles. The blanks were examined using optical microscopy (Fig. 2), scanning electron microscopy, X-ray spectrometry and thermogravimetry. They were found to contain three phases: an ethylene-propylene copolymer, grey fibres (PET) and a calcium carbonate filler. 


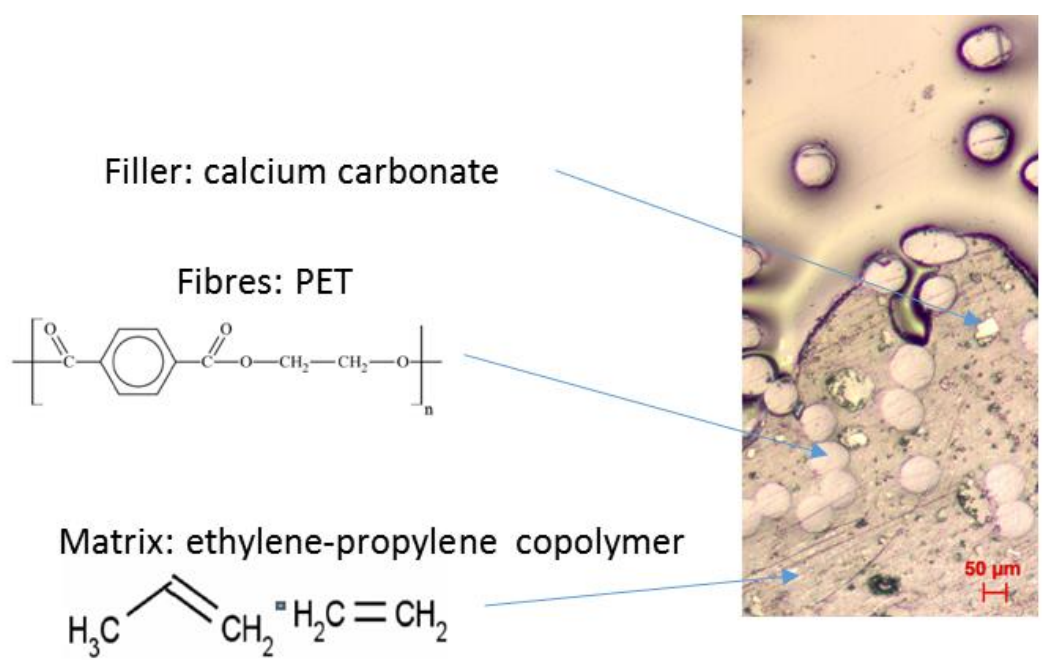

Fig. 2. The material to be heated

\section{Heating equipment design}

The control unit chosen for this application was NI myRIO-1950. It is a versatile measurement hardware card with control capabilities. In fact, it is a real-time (RT) computer with its own associated FPGA processor. It comprises 32 digital input/output ports (DIO), several analogue input ports (AI) and analogue output ports (AO), and a USB interface [8]. It can be used as an autonomous device or it can be controlled from a personal computer which doubles as a display unit. In software terms, Real-Time Linux ${ }^{\mathrm{TM}}$ (RTL) is the underlying system for the NI LabView tool (Fig. 3.) .

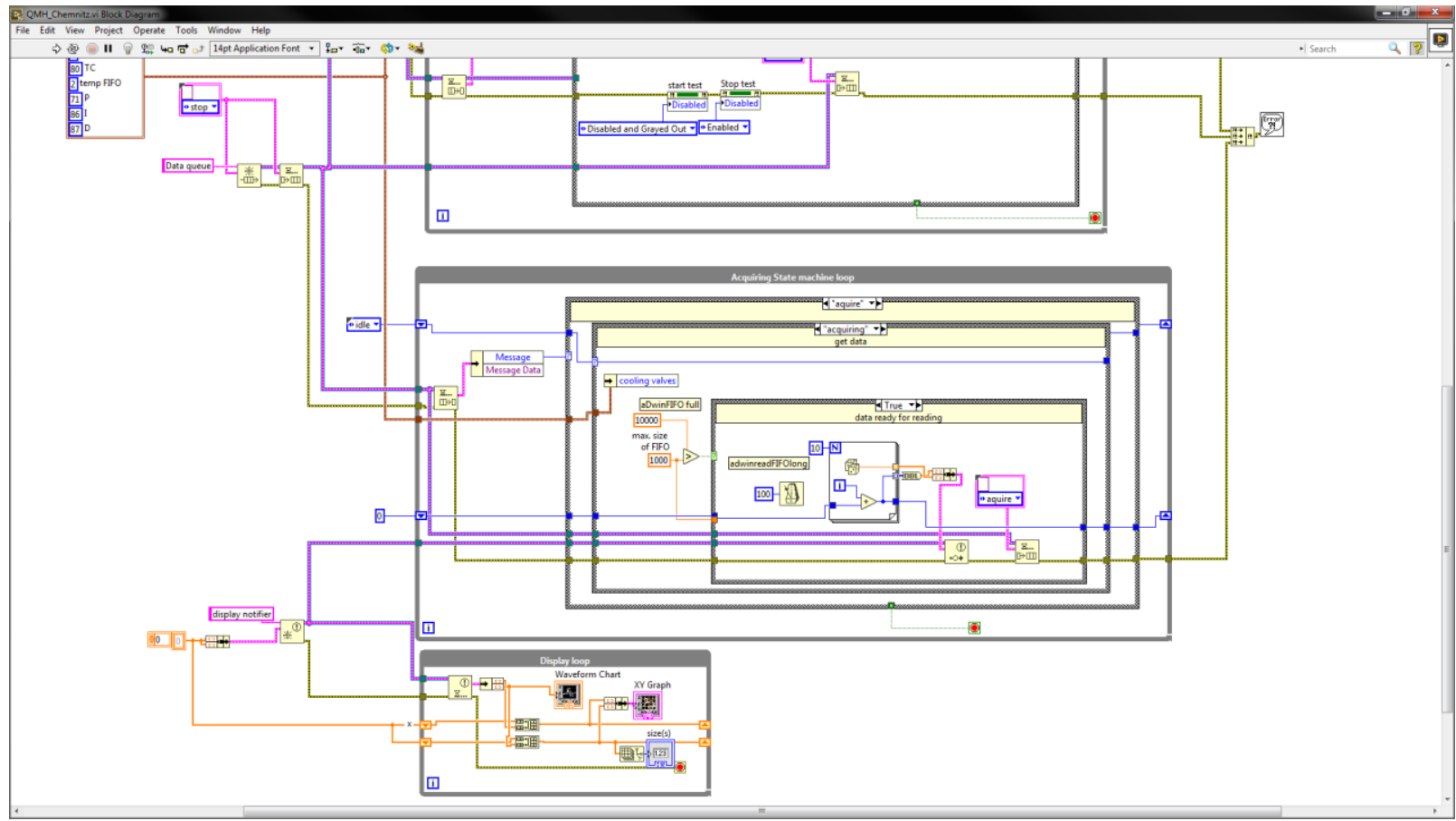

Fig. 3. LabVIEW development tool

Thanks to this configuration, the device offers a vast array of libraries. Programming thus becomes very intuitive. This applies particularly to the FPGA (Field Programmable Gate Array - an integrated circuit designed to be programmed by the customer [5]) because it removes the need for using special languages, such as VHDL (=VHSIC Hardware Description Language, VHSIC = Very High Speed Integrated Circuit [6]) or Verilog. Fig. 4 shows a block diagram with components that communicate with the control unit. Infrared quartz emitters Acim Jouanin QFE650 were chosen as heating elements. They offer several advantages: a short ramp-up time, short working distance from the surface being heated, a wide range of wavelengths, a very low thermal inertia and low radiation reflectance. The emitters are switched from the control unit via a power unit comprising SSR relays with optocouplers. 


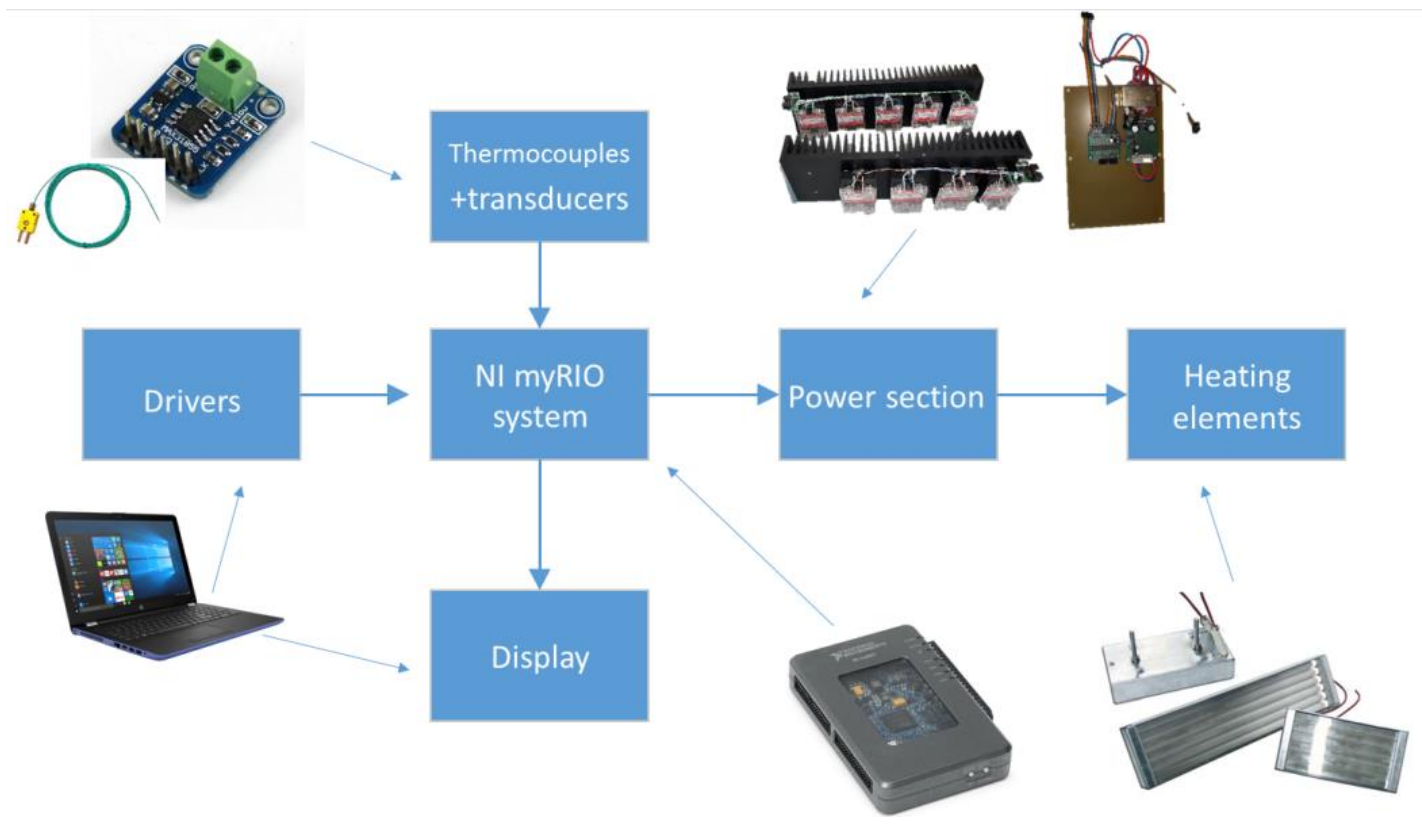

Fig. 4. Block diagram of the heating equipment

The system's design comprises three layers. The bottom layer consists of the FPGA which provides the SPI (Serial Peripheral Interface) for communication with thermocouple modules. The reason for this is that the functionalities of conventional SPI libraries are limited, making them unsuitable for direct interaction with the modules. The remaining capacity of the FPGA will provide safety functions. It could also perform auxiliary calculations, such as PID control, but those are not needed in this case, as the capacity of the RT section is sufficient for the application.

The middle layer is the RT section which supports the core of the monitoring and control program. The third layer is the operator interface running on a personal computer. The communication between the RT and FPGA is provided internally. An ethernet interface will support the communication between the RT section and the personal computer. This arrangement enables the system to operate autonomously without being connected to a personal computer. Regulation and safety functions can thus be fulfilled independently of the user. The computer interface supports not only the display and storage of gathered data but also the transmission of commands to the main program running on the RT section.

\section{Heating equipment design}

Below, individual parts of the structure are described and their selection and designs are clarified. Some components were chosen on the basis of calculations, others on recommendation from manufacturers' engineering departments and still others on the basis of information from manuals. The final design of the equipment for heating organic polymerbased composites is presented in Figures 5 and 6 . It is closely tied to the configuration of the mould and the process sequence for shaping organic polymer-based composites, as described in section 2 . The design was developed using the NX 10 software which offers functionalities which are essential for designing, design process management and data sharing.

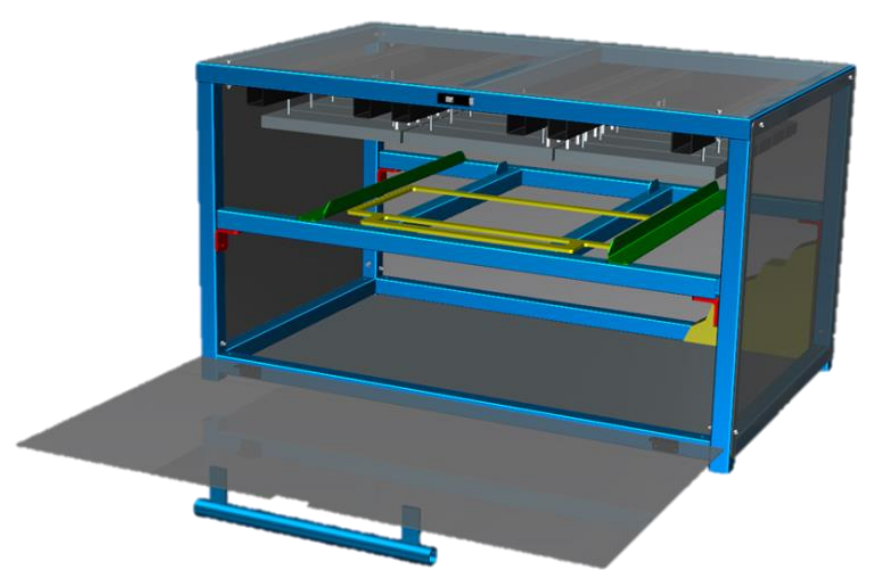




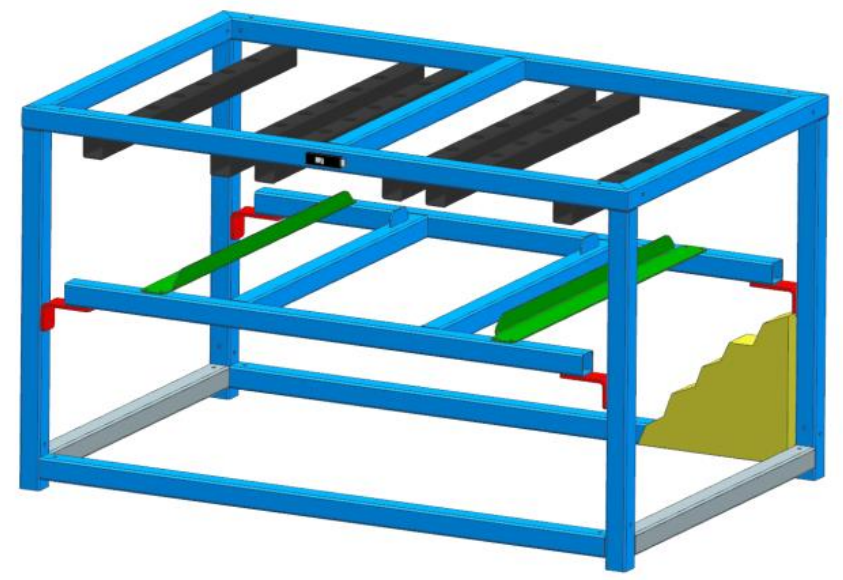

Fig. 5. Final design of heating equipment for moulding organic polymer-based composites

As Figures 5 and 6 show, the main load-bearing component of the equipment is a frame assembled from aluminium sections manufactured by ALUTEC KK. To protect the operator from contact with hot surfaces, the frame is covered on all sides with metal guards attached with M5 screws and nuts. Heat insulation of $30 \mathrm{~mm}$ thickness is bonded to the inner side of the metal guards and to the floor in order to minimize heat losses. The insulation material is SILCA $250 \mathrm{KM}$ calcium-silicate boards. They are lightweight boards with heat resistance up to $1000^{\circ} \mathrm{C}$ [7].

An electronic control unit is attached to the top of the frame with four M5 bolts. Its safety guard protects the operator from electric shock. Brackets for mounting emitters are attached to the top of the frame as well. Since the emitters include M5×35 screws and the side metal guards need to be insulated from the heat from the emitters, the brackets have holes for a spanner in the top wall of their hollow square sections, enabling the emitters to be bolted only to the bottom wall of the section. Supply cable harnesses are routed between the emitter brackets toward the top wall and through holes into the electronic control compartment.

In the central space of the equipment, there are cross members of hollow square sections on which a frame with a tensioned blank will rest. To secure the frame in the appropriate position, guide bars are attached along the sides, and stop blocks are installed at the back.

Hinged doors are provided in the front of the equipment to enable access to the working compartment. Using a handle, they can open vertically toward the ground and can be locked closed with a pull bar. The blank to be heated is placed and centred on the frame and attached along all sides with a clamping frame.

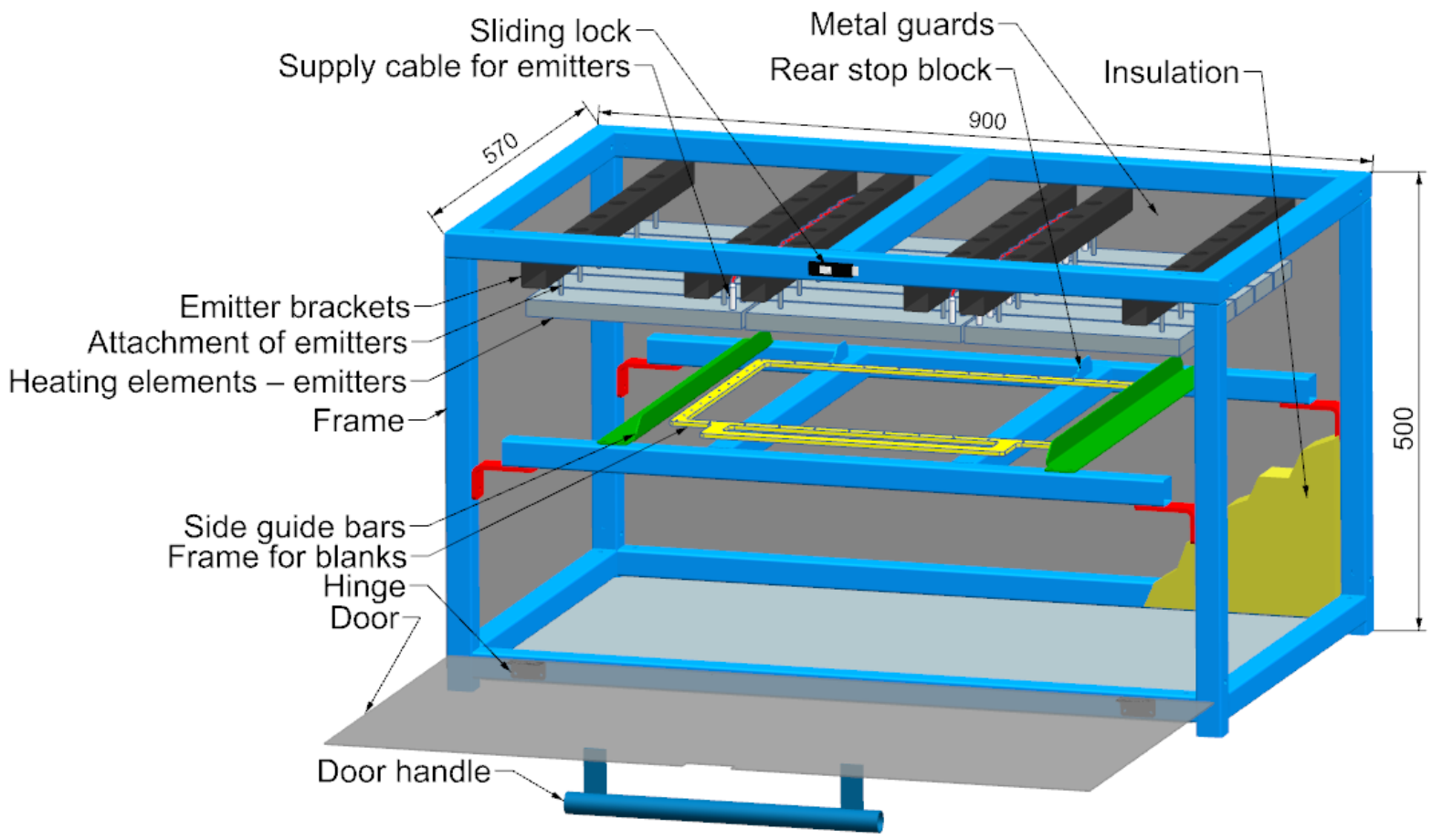

Fig. 6. Basic dimensions and descriptions of major components 


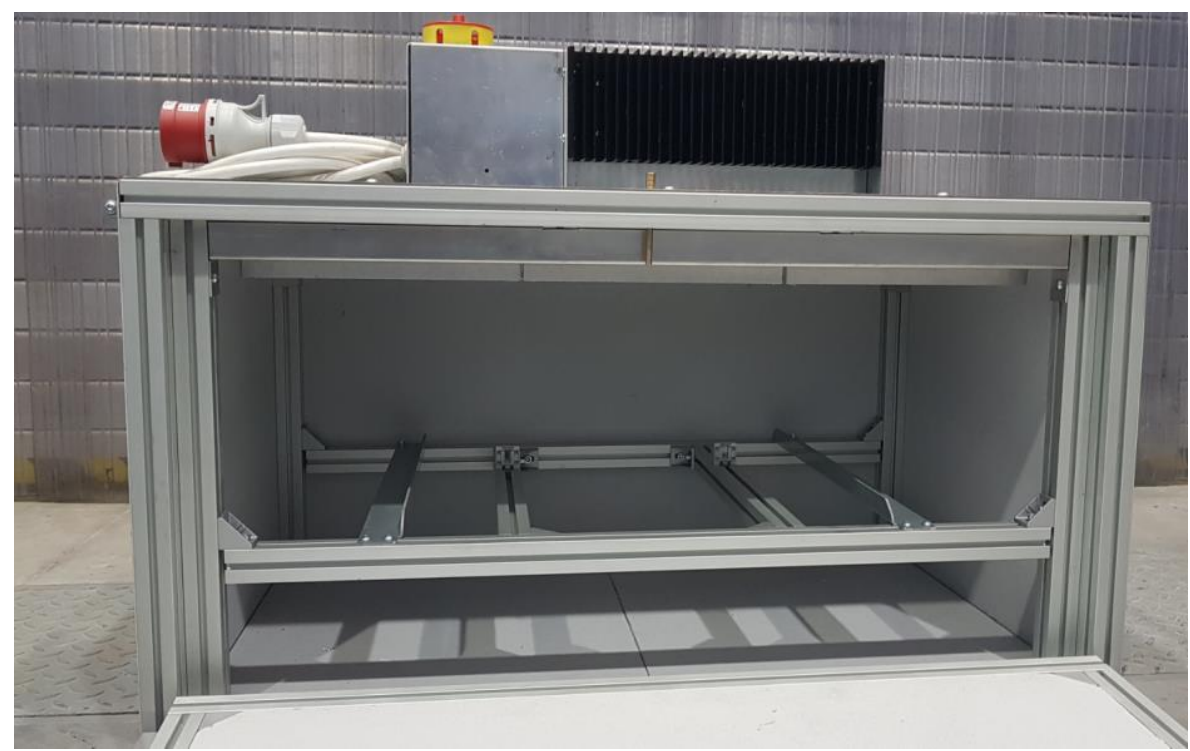

Fig. 7. Assembled prototype

\section{Conclusion}

These days there is not commercially available heating equipment for forming of composite materials on a polymeric-organic basis, that would meet the experimental requirements. Therefore the topological and geometric structure of heating systems was proposed in the paper. A design of the facility was carried out in the Siemens NX software.

The design is the first step in developing an experimental programme of research into moulding of organic polymerbased composite materials. Functional heating equipment is now available (Fig. 7) for moulding organic polymer-based composite materials. The regulator and control software for heating will be optimized in the next step. Furthermore, the design of a thermo-mechanical simulator for determination of the elastic-plastic properties of the material during forming will be proposed. With this device, research into and characterization of the effect of recyclable fillers on the moulding process.

\section{Acknowledgments}

The present contribution has been prepared under project LO1502 'Development of the Regional Technological Institute'under the auspices of the National Sustainability Programme I of the Ministry of Education of the Czech Republic aimed to support research, experimental development and innovation.

\section{References}

[1] S.M. Sapuan. (2017). Composite Materials: Concurrent Engineering Approach, Butterworth-Heinemann, ISBN 9780128025079

[2] Ehrenstein, Gottfried W. (2006). Polymerní kompozitní materiály, Scientia, ISBN 978-80-86960-29-6, Praha

[3] Steidl, J. (2005). Plasty a kompozity naplňují materiálové požadavky moderního strojírenství. MM Průmyslové spektrum, Vol. 2005, No 1., 35 -36, ISSN 1212-2572

[4] Tomkova, A. (2018). Využití predikce vlastností kompozitů s textilní výztuží pro optimalizaci výrobního procesu, Available from: https://www.researchgate.net/publication/228815572_Vyuziti_predikce_vlastnosti_kompozitu_s_textilni_vyztuzi_ pro_optimalizaci_vyrobniho_procesu :2018-08-10

[5] Lamza S, Sučić V. (2014). Comparison of Signal Switching Matrices for Remote Laboratories and a Novel Solution Using FPGA Technology, Procedia Engineering, Volume 69, Pages 844-851, ISSN 1877-7058

[6] Mealy, B.; Tappero, F. (2012) Free Range VHDL, Available from: http://www.freerangefactory.org/dl/free_range_vhdl.pdf: 2018-09-13.

[7] https://www.kamnakrby.cz/izolacni-deska-silca-250-km-30-mm, (2018). Azetko s.r.o., Izolační deska SILCA 250 KM 30 mm, Accessed on: 2018-08-13

[8] www.ni.com/en-gb/support/model.myrio-1950.html, (2018). National Instruments, User Guide and Specifications myRIO-1950, Accessed on: 2018-08-13

[9] Káňa, J.; Vorel, I.; Ronešová, A. (2015) Simulator of Thermomechanical Treatment of Metals, In DAAAM 2015. Vienna: DAAAM International Vienna, pp. 0513-05018, ISBN: 978-3-902734-07-5, ISSN: 1726-9679 